\title{
Antagonistic activity of cellular components of Pseudomonas species against Aeromonas hydrophila
}

\author{
Basanta Kumar Das*, Surya Kanta Samal, Biswa Ranjan Samantaray, \\ Satyanarayana Sethi, Phalguni Pattnaik, Bibhudendu Kumar Mishra \\ Aquatic Animal Health Division, Central Institute of Freshwater Aquaculture (CIFA), \\ P. O. Kausalyaganga, Bhubaneswar-751002, Orissa, India
}

Received 5 January 2004; received in revised form 15 January 2005; accepted 31 January 2005

\begin{abstract}
Antagonistic effects of Pseudomonas fluorescens, P. aeruginosa and P. putida were studied against 12 strains of Aeromonas hydrophila (Ah1-Ah12). Four different fractions of cellular component (i.e. whole cell product, heat killed whole cell product, intra cellular product and extra cellular product) of all Pseudomonas species were equally effective in reducing growth of $A$. hydrophila strains, as measured by the zone of inhibition in an in vitro sensitivity test and have potential action against $A$. hydrophila infection in fishes.
\end{abstract}

(C) 2005 Elsevier B.V. All rights reserved.

Keywords: Biocontrol; Pseudomonas spp.; Aeromonas hydrophila

\section{Introduction}

Control of microbial communities with high species diversity in nature has been regarded as difficult (Maeda, 1994). Such types of microbial communities can disperse the effect caused by the inversion or addition of certain extrinsic pathogenic organisms. In addition, microorganisms can be sources of a variety of bioactive natural products of basic

\footnotetext{
* Corresponding author. Tel.: +91 6742465446 * 228/235 (O); 2350756 (R); fax: +916742465407.

E-mail address: basantadas@yahoo.com (B.K. Das).
}

research and commercial interest that have inhibitory effect on microbial growth (Reichelt and Borowitska, 1984; Cannell et al., 1988). In aquaculture practices bacterial infectious diseases result in losses worldwide and to prevent them antimicrobial compounds are used intensively. In the process of antibiotic treatment, drug resistance patterns can develop within the pathogenic microbial community. Therefore, alternatives to the use of antibiotics are gaining importance in many countries (Nogami and Maeda, 1992; Sugita et al., 1998; Gatesoupe, 1999; Bala Reddy, 2001). Accordingly, the application of microbial communities in aquaculture for controlling pathogenic bacteria shows promise. 
Most of the antibiotics used today are of microbial origin. In medicine, problem with pathogenic microbes becoming increasingly resistant against most commonly used antibiotics is being experienced (Cowen, 2001; Lipsitch, 2001). Then some derivatives of the antibiotics circumvent or even prevent rapid mutation to resistance of the pathogens (Hughes, 2003). The Pseudomonas species as a fungicide to protect the food from toxic fungi such as penicillium and botrytis. The protein patterns of the different strains of Staphyloccus aureus and Lactobacillus sanfranciscensis are resistant to specific antibiotics (De Angelis et al., 2001; Cordwell et al., 2002; Hecker et al., 2003).

A similar approach was also undertaken in the culture of Phyllosoma larvae of spiny lobster Jasus edwardsii (Igarashi et al., 1990). It has been recorded that antimicrobial substances produced by some bacteria seem to play an important role in antagonising other bacteria in aquatic ecosystems (Dopazo et al., 1988; Sugahara et al., 1988). It has also been reported that intestinal bacteria from turbot show an inhibitory effect on fish pathogenic bacteria (Westerdahl et al., 1991; Olsson et al., 1992; Sugita et al., 1997). As these bacteria are natural inhabitants of the aquatic system, they could persist for a relatively longer period and might inhibit establishment of fish pathogens in the aquatic environment as well as in the fish host. Therefore, this preliminary in vitro study was undertaken to examine the antibacterial properties of Pseudomonas fluorescens, $P$. aeruginosa and $P$. putida against the fish pathogenic bacteria Aeromonas hydrophila for the first time.

\section{Materials and methods}

\subsection{Isolation of bacteria}

Diseased fishes showing various lesions on the skin and in the musculature, and healthy fishes were used for isolation of bacteria. Pseudomonas isolation agar (Hi media, India) was used for isolation of pure cultures of Pseudomonas species. P. fluorescens (PF1) was isolated from the liver of goldfish (Carassius auratus), $P$. aeruginosa (PA1) was isolated from the intestine of climbing perch (Anabas testudineus) and P. putida (PP1) was isolated from skin lesions of rohu
(Labeo rohita). The 12 strains of $A$. hydrophila isolated from skin lesion, liver, kidney and intestine of mrigal, cat fish, goldfish and murrels were taken to study the antagonistic activity against different cellular components of Pseudomonas species. The different species of Pseudomonas and A. hydroplhila strains were selected and characterized based on their biochemical properties (Holt and Krieg, 1984). Dominant isolates were purified and identified using conventional biochemical tests described by Mac Fadden (1976) and West and Colwell (1984). A. hydrophila (Ah1-Ah12) strains isolated from different organs such as liver and kidney, as well as swabs of skin lesions of various freshwater fishes maintained in the laboratory were also used for the present study. A. hydrophila after $24 \mathrm{~h}$ of incubation in nutrient broth was streaked on Rimler-Shott's medium (Hi media, India) for purity. Twelve strains of A. hydrophila were used for the antagonistic study against heat killed whole cell product (HK WCP), whole cell product (WCP), intra cellular product (ICP) and extra cellular product (ECP) of the Pseudomonas species.

\subsection{Preparation of different cellular components}

Four types of antigenic components, e.g. heat killed whole cell product (HK WCP), whole cell product (WCP), intra cellular product (ICP) and extra cellular product (ECP) were prepared from $P$. fluorescens, $P$. aeruginosa and $P$. putida. Briefly pure cultures of all the bacteria (PF1, PA1 and PP1) were grown separately in sterile conditions in $250 \mathrm{ml}$ of brain heart infusion broth (Hi media, India) at $30{ }^{\circ} \mathrm{C}$ for $24 \mathrm{~h}$. Pure cultures of each bacterium were divided into five equal volumes of $50 \mathrm{ml}$ and each $50 \mathrm{ml}$ was taken for preparation of HK WCP, WCP, ECP and ICP separately. The optical density (OD) of $24 \mathrm{~h}$ old cultures was taken for each bacterium and simultaneous plating was carried out in triplicate and the colony forming unit $/ \mathrm{ml}$ was calculated. The optical density at $546 \mathrm{~nm}$ of $P$. fluorescens was 0.836 which corresponded to $1.9 \times 10^{9} \mathrm{cfu} / \mathrm{ml}$, whereas an OD of $P$. aeruginosa 0.742 corresponded to $1.2 \times 10^{9} \mathrm{cfu} / \mathrm{ml}$ and an OD of $P$. putida, 0.738 corresponded to $2.1 \times 10^{9} \mathrm{cfu} / \mathrm{ml}$ respectively. The protein estimation of all the protein fraction of Pseudomonas species was according to Bradford (1976). The minimum amount of protein content $(70 \mu \mathrm{l})$ of the lowest protein 
concentration of Pseudomonas species was taken as standard and accordingly the other protein fractions of other Pseudomonas species were calculated and charged in nutrient agar plates.

\subsection{Whole cell product (WCP)}

All the bacteria (P. fluorescens, P. aeruginosa and $P$. putida) grown separately in brain heart infusion broth were harvested after $24 \mathrm{~h}$ incubation and centrifuged at $10,000 \times g$ for $10 \mathrm{~min}$ at $4{ }^{\circ} \mathrm{C}$. The bacterial pellet was washed twice and resuspended in phosphate buffered saline (PBS) (pH 7.2) and used for the antagonistic study.

\subsection{Extra cellular product (ECP)}

The supernatants obtained after centrifuging $24 \mathrm{~h}$ old cultures of bacteria in brain heart infusion broth were filtered $(0.22 \mu \mathrm{l})$. They were further concentrated with $20 \%$ PEG 6000, dialysed against PBS (pH 7.2) and used as ECP.

\subsection{Heat killed whole cell product}

Pseudomonas cultures grown in bulk were harvested by centrifugation at $10,000 \times g$ for $10 \mathrm{~min}$ at 4 ${ }^{\circ} \mathrm{C}$. The bacterial pellet was washed twice and resuspended in phosphate buffered saline $(\mathrm{pH}$ 7.2). They were heat killed at $60{ }^{\circ} \mathrm{C}$ for $1 \mathrm{~h}$ in a water bath and finally stored at $-20{ }^{\circ} \mathrm{C}$.

\subsection{Intra cellular product (ICP)}

All the bacteria (P. fluorescens, P. aeruginosa and $P$. putida) were grown separately in brain heart infusion broth and centrifuged at $10,000 \times g$ for $10 \mathrm{~min}$ at $4{ }^{\circ} \mathrm{C}$. The bacterial pellet was washed twice and re-suspended in phosphate buffered saline (pH 7.2), to $2 \%$ of the initial volume. The cell pellets were then sonicated at $50 \mathrm{~Hz}$ for 5 min (Artelk Sonic Dismembrator model 150) filtered through a syringe with a $0.45 \mu \mathrm{l}$ filter and finally stored at $-20{ }^{\circ} \mathrm{C}$ until further use.

\subsection{Biocontrol study}

Overnight growth cultures of different strains of A. hydrophila were incubated on Tryptone Soya agar (Hi media, India) plates separately by the lawn culture method. Then $6 \mathrm{~mm}$ diameter wells were made in each plate with the help of a well puncture (Hi media, India) and $70 \mu \mathrm{l}$ of whole cell product (WCP) corresponding to $2.1 \times 10^{9} \mathrm{cfu} / \mathrm{ml}$, extracellular product (ECP) corresponding to $1.12 \times 10^{8} \mathrm{cfu} /$ $\mathrm{ml}$, heat killed WCP corresponding to $1.3 \times 10^{8} \mathrm{cfu} /$ $\mathrm{ml}$ and intra cellular product (ICP) corresponding to $1.7 \times 10^{8} \mathrm{cfu} / \mathrm{ml}$ were charged in the respective wells of different $A$. hydrophila plates and incubated at $37{ }^{\circ} \mathrm{C}$ for $24 \mathrm{~h}$. The zone of inhibition around the charged well was recorded after incubation. Simultaneously, control samples were maintained with sterile phosphate buffer saline $(\mathrm{pH}$ 7.2) placed into the respective wells prepared as mentioned above. In all the cases, the triplicate plates were maintained along with the PBS control for biocontrol study.

Selected antibiotics, Chloramphenicol $(30 \mathrm{mcg})$, nalidixic acid $(30 \mathrm{mcg})$, furazolidone $(50 \mathrm{mcg})$, norfloxacin $(30 \mathrm{mcg})$, oxytetracycline $(30 \mathrm{mcg})$, ciprofloxacin $(15 \mathrm{mcg})$, gentamycin $(15 \mathrm{mcg})$ and nitrofurantoin $(10 \mathrm{mcg})$ were tested in a diagnostic sensitivity medium (Hi media, India) against different A. hydrophila strains to compare the effectiveness of different cellular components of Pseudomonas species.

A required amount of diagnostic sensitivity medium (DST) (Hi media, India) was prepared. Sterile petriplates (98 mm diameter) were poured with $20 \mathrm{ml}$ DST medium and allowed to solidify at room temperature. A. hydrophila cultures were inoculated by the lawn culture method. Then the above antibiotics were placed in different cultured plates and incubated at $37{ }^{\circ} \mathrm{C}$ for $24 \mathrm{~h}$. After incubation the observations were noted. The zones of inhibition of each product were compared with the recommended zone of inhibition of the antibiotics against the cultures. The zones of inhibition of the antibiotics against the A. hydrophila strains were treated as positive control.

\subsection{Statistical analysis}

All the data were analyzed by running the general linear model program available in SAS software. The means were compared using Duncan's multiple range test (Duncan, 1955) to find the difference at $5 \%$ $(P<0.05)$ level. 


\section{Results}

\subsection{Protein estimation of different cellular components of Pseudomonas species}

The protein contents of ICP, WCP, HK WCP and ECP of P. fluorescens were 5.13, 4.91, 4.85 and 4.75 $\mathrm{mg} / \mathrm{ml}$ respectively. Similarly, the protein contents of ICP, WCP, HK WCP and ECP of $P$. aeruginosa and $P$. putida were $6.21,5.97,5.73,5.63,5.72,5.31,4.85$ and $4.72 \mathrm{mg} / \mathrm{ml}$ respectively. The ICP of $P$. aeruginosa contain highest protein concentration $(6.21 \mathrm{mg} /$ $\mathrm{ml}$ ) and lowest protein content in ECP of P. putida $(4.72 \mathrm{mg} / \mathrm{ml})$. The minimum quantity of protein fraction $(70 \mu \mathrm{l})$ charged on nutrient agar plate against A. hydrophila strains of $P$. putida ECP was found to be $340 \mu \mathrm{g}$. Equal protein concentration per mililitre of each cellular components of the bacteria was adjusted to $340 \mu \mathrm{g}$ corresponded to $70 \mu \mathrm{l}$.

\subsection{Biocontrol study using P. fluorescens (PF1)}

Results obtained from the WCP, HK WCP, ECP and ICP of PF1 against A. hydrophila are shown in Fig. 1. It was revealed that the ECP of PF1 was found to be highly effective and produced a zone ranging from 60 to $85 \mathrm{~mm}$ against Ah1 to Ah12 strains (Fig. 1). The highest recorded zone was observed with Ah10 isolated from skin lesions of Channa marulius followed by Ah6 $(81.33 \pm 2.60 \mathrm{~mm})$. ECP of PF1 against Ah11 produced a mean zone size of $72.33 \pm 0.88 \mathrm{~mm}$. Similarly, WCP, HK WCP and ICP of PF1 were equally effective and had a bactericidal effect against all strains of $A$. hydrophila (Fig. 1). Out of the four product components of PF1, ECP produced the highest activity in almost all cases, except for Ah9. WCP of PF1 was also equally effective as the ECP and the inhibitory activity was highest in Ah1, Ah3, Ah6, Ah7, Ah8, Ah9 when compared to ICP and HK WCP (Fig. 1) as compared to PBS control $(0 \mathrm{~mm})$. Significant differences $(P \leq 0.05)$ of inhibitory effects were recorded in all the cases as compared to positive control.

\subsection{Antagonistic study using P. putida (PP1)}

The zones of inhibition produced by PP1 against Ah1 to Ah12 are shown in Fig. 2. The zone size of heat killed WCP of PP1 was highly effective and produced zones ranging from 52 to $71 \mathrm{~mm}$. The

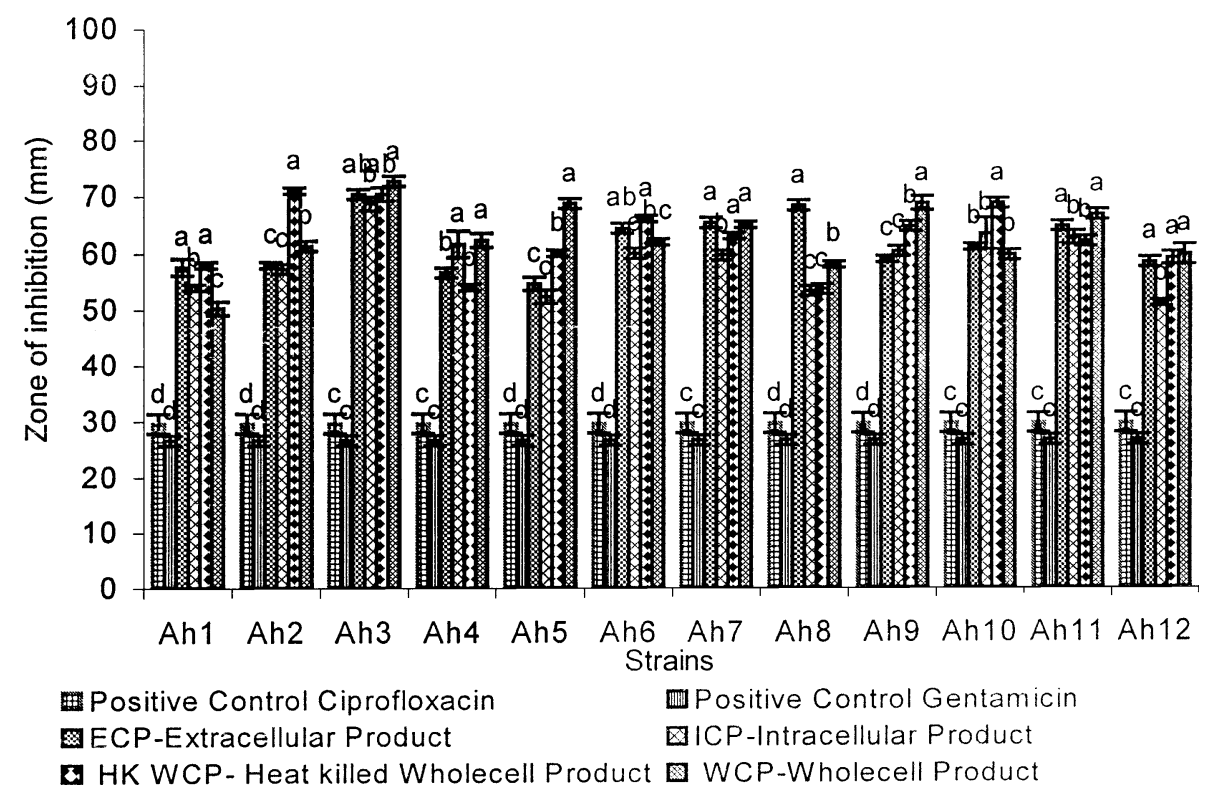

Fig. 1. Zones of inhibition of four crude fractions of $P$. fluorescens against $A$. hydrophila strains. (Values are represented as mean \pm S.E., mean bearing common superscript are not significant to each other.) 


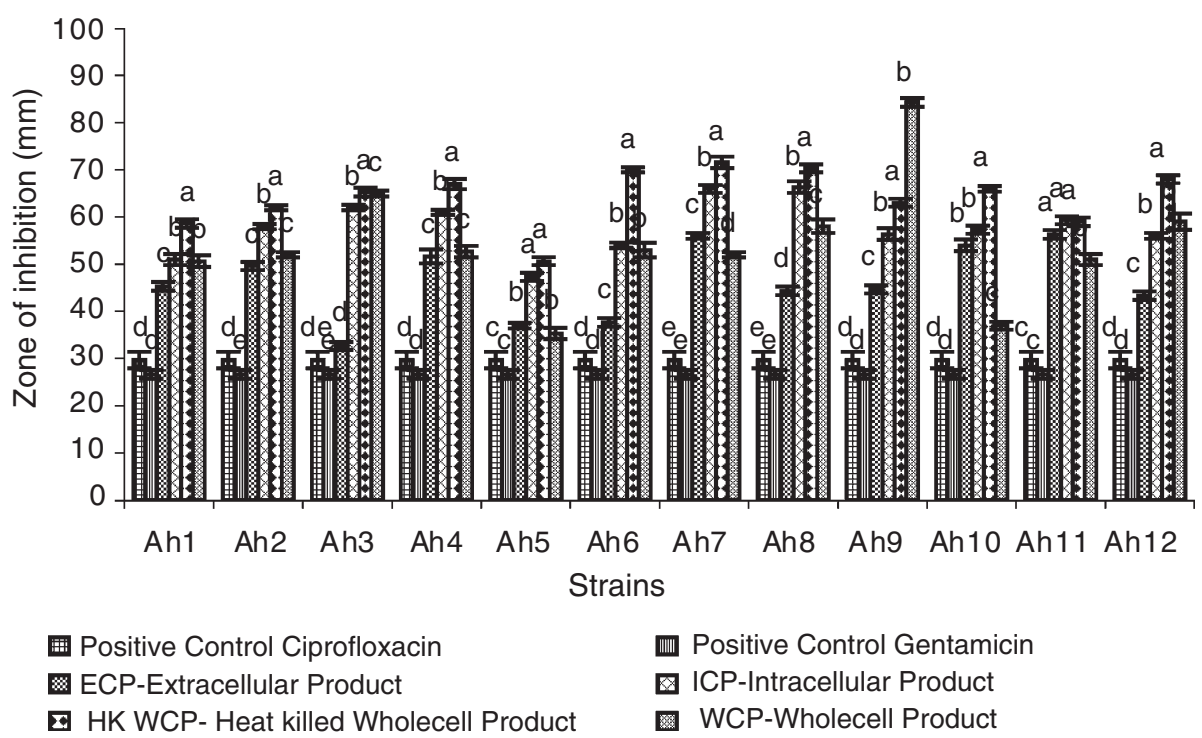

Fig. 2. Zones of inhibition of four crude fractions of $P$. putida against $A$. hydrophila strains. (Values are represented as mean \pm S.E., mean bearing common superscript are not significant to each other.)

overall activity of HK WCP was the highest among the four product fractions tested and found significantly different $(P \leq 0.05)$ as compared to the positive control. Whereas WCP of PP1 produced zone inhibition ranging from 38 to $55 \mathrm{~mm}$; ICP of PP1 produced zones ranging from 46 to $68 \mathrm{~mm}$ and ECP of PP1 produced a zone size from 34 to $56 \mathrm{~mm}$. The least bactericidal activity was recorded in the case of ECP of PP1 against Ah3 and the highest recorded bactericidal activity of PP1 against Ah6 indicating the effectivity of WCP of PP1 against Ah1 as compared to PBS control $(0 \mathrm{~mm})$. All the four cellular components showed significant $(P \leq 0.05)$ inhibitory activity against 12 strains of $A$. hydrophila (Fig. 2) when compared to the positive control.

\subsection{Antagonistic study of P. aeruginosa (PA1)}

The four cellular components of PA1 were tested as antagonistic agents/components against $A$. hydrophila (Fig. 3). All the four fractions produced antagonism as measured by the zone of inhibition greater than 52 $\mathrm{mm}$ and were found significantly different $(P \leq 0.05)$ as compared with the positive control. WCP of PA1 produced highest antagonism against Ah3 $(72.66 \pm 0.88 \mathrm{~mm})$ followed by HK WCP against Ah3 $(70.33 \pm 1.20 \mathrm{~mm})$ and Ah2 $(71.00 \pm 0.57 \mathrm{~mm})$.
WCP of PA1 produced a zone of $62.00 \pm 0.57 \mathrm{~mm}$ against Ah6 and ICP of PA1 produced a zone of $57.33 \pm 0.88 \mathrm{~mm}$ against the Ah2 strain as compared to the PBS control $(0 \mathrm{~mm})$.

\subsection{A. hydrophila}

A. hydrophila strains as Ah2, Ah3, Ah4, Ah5, Ah6, Ah10, Ah11 and Ah12 against P. fluorescens showed significant $(P<0.05)$ difference in ECP compared to other extracts as well as control; Ah7 and Ah8 did not show any significant difference among the extracts tested. A. hydrophila strain (Ah9) showed significantly highest zone of inhibition of WCP compared to control and other extracts. The extracts obtained from $P$. putida showed significantly $(P<0.05)$ highest zone of inhibition in HK WCP extract against $A$. hydrophila strains compared to control and other extract tested. Whereas, WCP of $P$. putida showed significantly highest zone of inhibition in Ah9 strains of $A$. hydrophila. The extracts obtained from $P$. aeruginosa showed significantly highest zone of inhibition in ECP against $A$. hydrophila strains compared to control and other extracts tested. Where as, WCP of $P$. aeruginosa showed significantly highest zone of inhibition in Ah3, Ah5 and Ah9 strains of $A$. hydrophila respectively. 


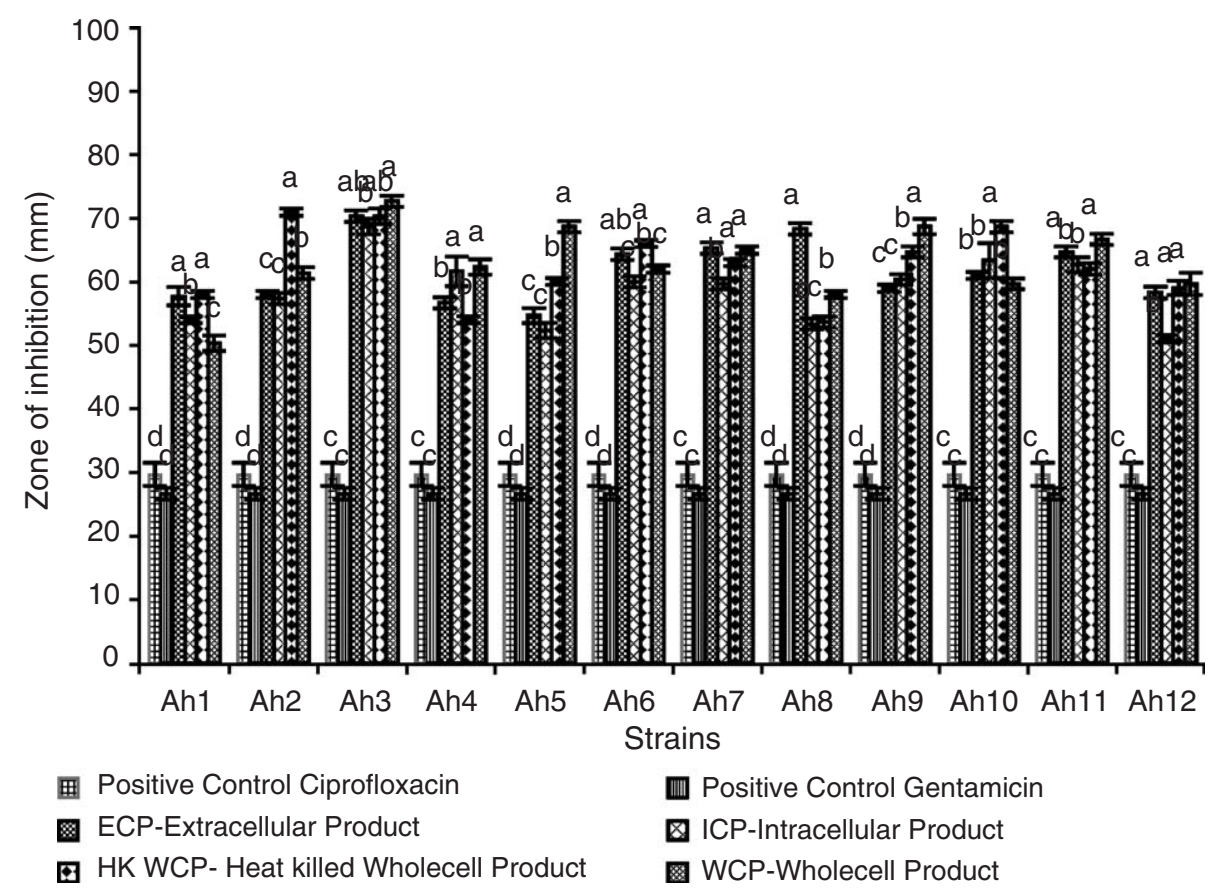

Fig. 3. Zones of inhibition of four crude fractions of $P$. aeruginosa against $A$. hydrophila strains. (Values are represented as mean \pm S.E., mean bearing common superscript are not significant to each other.)

\subsection{Drug sensitivity test}

The tested drugs used in the present experiment to compare the zone of inhibition with that of the four products of PF1, PP1 and PA1; produced zones ranging from 21 to $33 \mathrm{~mm}$ against $\mathrm{Ah1}-\mathrm{Ah} 12$, which was much lower, when compared to the four product fractions of PF1, PP1 and PA1.

\section{Discussion}

The antibacterial effect of bacteria is generally due to either individual or joint production of antibiotics, bacteriocins, siderophores (Gram and Melchiorsen, 1996), lysozymes and proteases and alteration of $\mathrm{pH}$ by organic acid production (Sugita et al., 1998). The inhibition due to such compounds is highly dependant on the experimental conditions, which are different in vitro and in vivo (Gatesoupe, 1999). Sugita et al. (1998) isolated a strain of Bacillus species that was antagonistic to $63 \%$ of the isolates from fish intestine. According to these authors, most pathogenic strains of
Vibrio or Aeromonas have been targeted in vitro tests. Other workers have also attempted to use other pathogens, e.g. Edwardsiella tarda, Enterococcus seriolicida, Pasteurella piscicida, Yersinia ruckeri (Dopazo et al., 1988; Austin et al., 1995; Ruiz et al., 1996; Sugita et al., 1996; Byun et al., 1997; Gibson et al., 1998). Some bacteria are antagonistic to viruses (Kamei et al., 1987, 1988; Direkbusarakom et al., 1998) and they may be efficient for biocontrol of viral diseases (Maeda et al., 1997). Antagonism of aquatic microbes to fish and shellfish pathogens has been reviewed by Gatesoupe (1999). The antagonistic properties of $P$. fluorescens to $V$. anguillarum in Lates niloticus (Gram et al., 1999) and P. fluorescens to A. salmonicida in Salmo trutta (Smith and Davey, 1993) have been reported and this inhibition is probably due to competition for free iron. In the present study, $P$. fluorescens, $P$. putida and $P$. aeruginosa however were antagonistic to A. hydrophila strains tested in the present study which were isolated from various disease conditions. The whole cell killed antigens, ECP, ICP and live bacteria of all the species were equally effective, as revealed by the zone of inhibition 
to all the tested strains of $A$. hydrophila. It was found that the antibiotics such as nalidixic acid, furazolidone, norfloxacin, oxytetracycline, ciprofloxacin, gentamycin and nitrofurantoin produced a zone size, which was much smaller than that of four cellular components of each bacterium tested.

Due to the increase in therapeutic resistance to the more commonly used antibiotics (Hjeltnes et al., 1987; Aoki, 1992; Nash et al., 1992) and its potential antipathogenic actions (by its intra and/or extra cellular products or whole cell products), there appears to be a potential for Pseudomonas spp. in the control of aquaculture diseases in fishes, particularly aeromoniasis. The inhibition caused by the Pseudomonad subcellular components is equally effective against the A. hydrophila strains. However, further assays are necessary especially in vivo, to forecast the concentration of ICP, ECP, WCP or live bacteria needed to antagonize or act as a biocontrol against $A$. hydrophila infection in fish. Hence research is urgently required on the antipathogenic metabolites excreted by Pseudomonads particularly $P$. fluorescens, P. putida and $P$. aeruginosa, which could potentially be used as substitutes to antibiotics.

\section{Acknowledgements}

The authors are very grateful to the Indian Council of Agricultural Research (ICAR), New Delhi for providing the financial assistance and the Director, Central Institute of Freshwater Aquaculture (CIFA), Bhubaneswar for providing facilities for the experiment.

\section{References}

Aoki, T., 1992. Chemotherapy and drug resistance in fish farms in Japan. In: Shariff, M., Subhasinghe, R.P., Arthur, J.R. (Eds.), Diseases in Asian aquaculture: 1. Proceeding of the First Symposium on Diseases in Asian Aquaculture, 1992, 26-29 November 1990, Bali, Indonesia, pp. 519-529.

Austin, B., Stuckey, L.F., Robertson, P.A.W., Effendi, I., Griffith, D.R.W., 1995. A probiotic strain of Vibrio alginolyticus effective in reducing diseases caused by Aeromonas hydrophila, Vibrio angullarum and Vibrio ordalii. J. Fish Dis. 18, 93-96.

Bala Reddy, B., 2001. Biofilm associated bacterial flora of a freshwater habitat. M. F. Sc. thesis. Central Institute of Fisheries Education, Mumbai, India, pp. 1-80.
Bradford, M.M., 1976. A rapid and sensitive method for the quantification of microgram quantities of protein utilizing the principle dye binding. Anal. Biochem. 72, 248-254.

Byun, J.W., Park, S.C., Benno, Y., Oh, T.K., 1997. Probiotic effect of Lactobacillus sp. DS-12 in flounder (Paralichthys olivaceus). J. Gen. Appl. Microbiol. 43, 305-308.

Cannell, R.J.P., Owsianka, A.M., Walker, J.M., 1988. Results of a large scale screening programme to detect antibacterial activity from freshwater algae. Br. Phycol. J. 23, 41-44.

Cordwell, S.J., Larsen, M.R., Cole, R.T., Walsh, B.J., 2002. Comparative proteomics of Staphylococcus aureus and the response of methicillin-resistant and methicillin-sensitive strains to Triton X-100. Microbiology 148, 2765-2781.

Cowen, L.E., 2001. Predicting the emergence of resistance to antifugal drugs. FEMS Microbiol. Lett. 204, 1-7.

De Angelis, M., Bini, L., Pallini, V., Cocconcelli, P.S., Gobbetti, M., 2001. The acid-stress response in Lactobacillus sanfranciscensis CBI. Microbiology 147, 1863-1873.

Direkbusarakom, S., Yoshimizu, M., Ezura, Y., Ruangpan, L., Danayadol, Y., 1998. Vibrio spp., the dominant flora in shrimp hatchery against some fish pathogenic viruses. J. Mar. Biotechnol. 6, 266-267.

Dopazo, C.P., Lemos, M.L., Lodeiros, C., Bolinches, J., Barja, J.L., Toranzo, A.E., 1988. Inhibitory activity of antibiotic-producing marine bacteria against fish pathogens. J. Appl. Bacteriol. 65, 97-101.

Duncan, D.B., 1955. Multiple range and multiple ' $F$ ' tests. Biometrics 11, 1-42.

Gatesoupe, F.J., 1999. The use of probiotics in aquaculture. Aquaculture 180, 147-165.

Gibson, L.F., Woodworth, J., George, A.M., 1998. Probiotic activity of Aeromonas media on the pacific oyster, Crassostrea gigas, when challenged with Vibrio tubiashii. Aquaculture 169, $111-120$.

Gram, L., Melchiorsen, J., 1996. Interaction between fish spoilage bacteria Pseudomonas sp. and Shewanella putrefaciens in fish extracts and on fish tissue. J. Appl. Bacteriol. 80, 589-595.

Gram, L., Melchiorsen, J., Spanggaard, B., Huber, I., Nielsen, T.F., 1999. Inhibition of Vibrio anguillarum by Pseudomonas fluorescens AH2, a possible probiotic treatment of fish. Appl. Environ. Microbiol. 65, 969-973.

Hecker, M., Engelmann, S., Cordwell, S.J., 2003. Proteomics of Staphylococcus aureus current state and future challenges. J. Chromat. B. Analty. Tech. Biom. Life. Sci. 787, 179-195.

Hjeltnes, B., Andersen, K., Egidius, E., 1987. Multiple antibiotic resistances in Vibrio salmonicida. Bull. Eur. Assoc. Fish Pathol. 7, 85-89.

Holt, J.G., Krieg, N.R., 1984. Bergey's Manual of Systematic Bacteriology vol. 1. Williams and Wilkins, Baltimore, USA.

Hughes, D., 2003. Exploiting genomics, genetics and chemistry to combat antibiotic resistance. Nat. Rev., Genet. 4, 432-441.

Igarashi, M.A., Kittaka, J., Kawahara, E., 1990. Phyllosoma culture with inoculation of marine bacteria. Nippon Suisan Gakkaishi 56 (11), 1781-1786.

Kamei, Y., Yoshimizu, M., Ezura, Y., Kimura, T., 1987. Screening of bacteria with antiviral activity against infectious hemato- 
poietic necrosis virus (IHNV) from estuarine and marine environments. Bull. Jpn. Soc. Sci. Fish. 53, 2179-2185.

Kamei, Y., Yoshimizu, M., Ezura, Y., Kimura, T., 1988. Screening of bacteria with antiviral activity from freshwater salmonid hatcheries. Microbiol. Immunol. 32, 67-73.

Lipsitch, M., 2001. The rise and fall of antimicrobial resistance. Trends Microbiol. 9, 438-444.

Mac Fadden, J.F., 1976. Biochemical Tests for the Identification of Medical Bacteria. Williams and Wikens Co, Baltimore. 310 pp.

Maeda, M., 1994. Biocontrol of the larval rearing biotope in aquaculture. Bull. Natl. Res. Inst. Aquacult., Suppl. 1, 71-74.

Maeda, M., Nogami, K., Kanematsu, M., Hirayama, K., 1997. The concept of biological control methods in aquaculture. Hydrobiologia 358, 285-290

Nash, G., Nithimathachoke, C., Tungmandi, C., Arkarjamorn, A., 1992. Vibriosis and its control in pond reared Penaeus monodon in Thailand. In: Shariff, M., Subasinghe, R.P., Arthur, J.R. (Eds.), Diseases in Asian Aquaculture: 1. Proceeding of the First Symposium on Disease in Asian Aquaculture, 26-29 November 1990, Bali. Indonesia, pp. 143-155.

Nogami, K., Maeda, M., 1992. Bacteria as biocontrol agents for rearing larvae of the crab, Portunus trituberculatus. Can. J. Fish. Aquat. Sci. 49, 2373-2376.

Olsson, J.C., Westerdahl, A., Conway, P.L., Kjelleberg, S., 1992. Intestinal colonization potential of turbot (Acophthalmus maximus) and dab (Limanda limanda) associated bacteria with inhibitory effects against Vibrio anguillarum. Appl. Environ. Microbiol. 58, 551-556.

Reichelt, J.L., Borowitska, M.A., 1984. Antimicrobial activity from marine algae: results of a large-scale screening programme. Hydrobiologia 116, 158-168.
Ruiz, C.M., Roman, G., Sanchez, J.L., 1996. A marine bacterial strain effective in producing antagonisms of other bacteria. Aquac. Int. 4, 289-291.

Smith, P., Davey, S., 1993. Evidence for the competitive exclusion of Aeromonas salmonicida from fish with stress-inducible furunculosis by a fluorescent pseudomonad. J. Fish Dis. 16, $521-524$.

Sugahara, I., Kimura, T., Hayashi, K., Nakajima, I., 1988. Distribution and generic composition of lytic enzyme-producing bacteria in coastal and oceanic bottom sediments. Nippon Suisan Gakkaishi 54 (6), 1011-1015.

Sugita, H., Matsuo, N., Shibuya, K., Deguchi, Y., 1996. Production of the antibacterial substances by intestinal bacteria isolated from coastal crab and fish species. J. Mar. Biotechnol. $4,220-223$.

Sugita, H., Shibuya, K., Hanada, H., Deguchi, Y., 1997. Antibacterial abilities of intestinal microflora of the river fish. Fish. Sci. 63, 378-383.

Sugita, H., Hirose, Y., Matsuo, N., Deguchi, Y., 1998. Production of the antibacterial substance by Bacillus sp. strain NM 12, an intestinal bacterium of Japanese coastal fish. Aquaculture 165, $269-280$

West, P.A., Colwell, R.R., 1984. Identification of Pseudomonadaceae: an overview. In: Colwell, R.R. (Ed.), Pseudomoniasis in the Environment. John Wiley, New York, USA, pp. 141-199.

Westerdahl, A., Olsson, J.C., Kjelleberg, S., Conway, P.L., 1991. Isolation and characterization of turbot (Scophthalmus maximus) associated bacteria with inhibitory effects against Vibrio anguillarum. Appl. Environ. Microbiol. 57, 2223-2228. 